\title{
Research on the English Teaching Theory and Practice from the Communicative Approach
}

\author{
Dan $\mathrm{Wu}^{1, \mathrm{a}}$ \\ ${ }^{1}$ The College of Post and Telecommunication of WIT, Wuhan, Hubei, China, 430073 \\ ${ }^{a}$ email,
}

Keywords: English Teaching, Theory, Practice, Communicative Approach

\begin{abstract}
This paper focuses on the challenges after joining the WTO brought about the concept of how to guide the reform of our communicative teaching foreign language teaching. The article reviews the development and current situation of foreign language teaching in Western countries, discuss the language acquisition theory, communicative teaching and student-centered teaching method of application. This paper also analyzes the problems of foreign language teaching, and proposed to solve problems, improve Discussion on Foreign Language Teaching.
\end{abstract}

\section{Introduction}

With China's accession to WTO, the community college graduates English proficiency requirements continue to increase. How combined with China's national conditions (Chinese cultural background and habits), through the communicative approach teaching and teaching mode of exploration and practice, train and improve students' communicative competence in English is very necessary, but also the responsibilities of the majority of English teaching workers. Abroad teaching in EFL / ESL teacher commonly used communicative approach. They cultivate students' communicative competence as an important part of classroom activities; its effect on how the quality of teaching as one of the test criteria, notable achievements. They think: classroom interaction between teachers and students' communication and interaction allows a second foreign language course "is full of exciting moments." To abandon the classroom teacher-centered teaching mode (teaching teachers spend a lot of time and ask questions, students answer ruling, summary, etc.). Language is the product of the human mind, with a psychological reality. Language as a social communication tool always social needs, social change along the trajectory of development. Communicative approach to foreign language teaching trends is advancing in this direction.

\section{The Function of Language and Communicative Competence}

"Communicative competence" is first proposed by the American sociologist Hymes, it is rethinking the British linguist Noam Chomsky "capacity" and the concept of re-understanding, which directly affects the development communicative teaching purposes; and British linguist Halliday discusses the function of language is the theoretical basis of Communicative language Teaching. "Capacity" refers to the speaker hearer's knowledge of the language, and "expression" refers to the actual use of language in specific situations. Hymes think Chomsky's "capacity" does not involve the use of language, not systematically consider it appropriate to use the language in social, he proposed his theory of "communicative capacity". "Communicative competence" means that people not only to acquire knowledge of the rules of language, but also get the social rules of the language in use.

\section{The Theory of Communicative Language Ability and Teaching Method}

In recent years, language teaching concept of structuralism has been questioned more and more experts, such as linguist Krashen states: When a grammar rule is only concerned with the correct language learners when the language to communicate, to the extent possible express the correct specification language, often seem hesitant, lack of language fluency, which lead to the failure of communication. Therefore, in order to teach the correct language rules and forms-based classroom 
model is likely to lead to the loss of the ability to accurately learners use the language in communicative language environment. In these three levels, language skills by a group composed of specific knowledge of the language. Strategic competence refers to the actual language of the communication process, the ability to use a variety of psychological knowledge of the language, so strategy is the ability to apply knowledge of language means of communication purposes. Psychophysiological mechanism refers to the psychological and neural processes of linguistic communication when used as a material phenomenon (sound, light) involved. Communicative approach is built on the basis of the theory of communicative language ability. Currently, the ability to develop learners communicative language teaching methods have been widely applied in English teaching. Communicative Approach theory, there are many strong views on language teaching and learning. Its main features are: ${ }^{1}$ all the activities around communication, that is, organized by teachers in the classroom, teaching all the activities carried out must be based on the communicative purpose as the center, should be for the purpose of communication services. The main mode of classroom driving task (task driven) based, that students complete the pre-set tasks to achieve the purpose of exercise ability to use language. They try to reproduce the communication process, namely in the classroom to reproduce the actual process of using the language as much as possible. Locale and tasks must have authenticity. Do not always correct the error. Many psychologists and linguists have discussed this frequently. In addition, CLT classroom is learner-centered classroom, students' needs is the goal of teaching.

From a historical point of view Teaching generated, there is every kind of teaching the theory of people's view of language, language learning Concept increasing awareness and in-depth results. In the analysis of the communicative approach to generate the development process, H DOU GLAS BROWN says: maturing in second language teaching and the process of development, we have experienced a lot of twists and turns and repeatedly. Recalling the history of the development of foreign language teaching, foreign language teaching to observe the difficult process of development in recent decades, and what kind of foreign language teaching to pursue the answer is almost certainly:? That is, we explore a communicative language teaching we are fighting. Higgs and Clifforal commented on the communicative approach is generated by the process: to promote the communicative approach is always painful. Because researchers concept of communicative competence defines repeated many times; learners must master many languages functions are repeated exploration; oral and written communicative discourse did a lot of tentative description, but also for non-language and Communicative language features have been verified many times. Only when the full grasp of many of these relevant knowledge, we ventured towards communicative language teaching goal. Indeed, look at the concept of communicative approach and the emergence and development of communicative teaching; from Chomsky to Hyams repeated definition of language and communicative competence; from Haiday large classification of language functions, to Coffey on applied to language teaching in 10 functionally ideas specific analysis and description; measure abstract ideal standard communicative competence from Hymes to Swain on the language ability of a particular application partition and patterns. All this suggests that despite the Communicative Approach to language teaching originated in the UK or European Union countries, but it is widely present in the solid theoretical basis of language learning and teaching theory continues to mature and develop above is an inevitable trend in the development of language, is generalized functional linguistics (including system functional grammar, sociolinguistics, applied linguistics, pragmatics and pedagogy) inevitable result of development. For this reason, regional communicative approach produced simply can not limit its implementation and development, on the contrary, not only outline the communicative approach in Europe caused a strong reaction, and then by countries around the world, including China, many educators, language teachers recognized, accepted and widespread, so communicative teaching ideas become the 20th century's most influential major foreign language teaching methods and approaches.

\section{The Practical Strategies of Communicative Approach}

Use of teaching skills in college English teaching is to develop students' language skills and 
communicative competence in the classroom in order to better implement the student-centered teaching principles, so that students have more time and opportunity to use the language, thereby teachers Tangguan change phenomenon fundamentally. Given the special nature of college English, teaching skills, in addition to having the characteristics of its general teaching skills, but also has its own characteristics.

College English classroom is a comprehensive classroom. Classroom, I heard that all aspects of reading and writing close convergence, mutual tolerance.

English language teaching is to develop not only language skills, but more importantly is to develop communication skills. Therefore, many teaching techniques are used to provide a variety of scenarios and opportunities for students to practice the language and communicative activities.

People speech acts always occurs in certain situations among and college English teaching is carried out in the native language environment. Thus, the teaching of English is required to provide students with a variety of scenarios, so that they learn to use language when the scene can meet the requirements. "Student-centered" teaching ideas throughout the teaching skills, reflecting the use of teaching techniques should mobilize students' initiative and enthusiasm.

Change the old teaching model and establish a new teaching philosophy is to train students' independent, spontaneous, the only way out independent learning ability. Dependent on teachers to classroom based teaching model should be converted to student autonomy, spontaneous, independent learning-based, instructor-supplemented teaching mode, that is, college English teaching mode should be "teacher-centered" to "student-centered."

Teacher-centered teaching model is dependent on the teacher around the classroom learning mode, students' learning activities are part of the teaching activities. Its role and function are diverse: (1) the organizer (Organizer), that is based on the content of teachers teaching materials, teaching purpose of communication activities such as design, scenarios and forms. (2) excited by (Motivator), that is, teachers strive to inspire students to participate in educational activities enthusiasm and consciousness, such as teachers in the classroom continue to make stimulating questions, always pay attention to each student to reflect, to arouse their thinking and participate in classroom desire to interact and so on. (3) Consultant (Counselor), that is, the teacher's role is not only to teach the language knowledge to guide drills, but to help students analyze, understand the problem, especially in the provision of communication activities related to language, culture, learning methods for students s help. (4) the chief architect of the students, that teachers will be teaching various activities certain stage of content organically combine to make the students through these activities continue to improve their English communication skills. Participants (5) communication activities, the teachers should be equal role with the students to participate as much as possible students' communication activities. This can eliminate the fear of students to teachers' psychological reaction to establish good relations with teachers and students.

Student-centered teaching model to promote students 'autonomous self independent learning, teachers teaching activity becomes a part of students' learning. Classroom teaching is student-centered, teacher supplement. In communicative teaching, the student's role is positive and active participants in teaching activities. Through the use of language to provide students with knowledge of the environment express his thoughts, fully stimulate students' English learning initiative to improve their English communication skills. These include: (1) Language, namely English grammar, vocabulary and mastery of language rules. (2) Social language skills of being able to properly use the language, so the language is adapted to the context of speech, the ability to their identity, social customs and the like. (3) The ability to speak and that can be coherent, fluent in the language learning ability. (4) The ability to raise a little, that difficulties or obstacles in the communication process, it is possible to use non-verbal means to overcome language difficulties or obstacles that prevent communication ability effectively to proceed.

The effective implementation of communicative teaching activities mainly by teachers and students interact in a medium of instruction (teaching content) role to be embodied. First, in the teaching content, emphasize the teaching as a tool to make use of authentic materials in textbooks, teaching unit of the title is to use the English language communication theme. In the teaching 
process, communicative teaching is not limited to a simple two-way communication, which emphasizes the combination of materials in the classroom content to design many scenarios, providing a large number of different types of language subjects English language input material in a timely manner to enable students to apply learned knowledge and communication activities through the language knowledge into skills. Communication activities can be combined in different domains of language and stylistic features of role-play, group discussions, exercises in pairs to solve a problem and other forms of implementation. In addition, in the teaching of communication, it should take into account the high and low grade students' knowledge of the English language, vocabulary, and comprehension of English cultural background the actual situation grasp. For younger students, you can organize more language game; for high school students can be more communicative with some debate competitions and other activities. Teachers should thoroughly study textbooks, teaching materials and to classify what kind of student autonomous learning tasks independently and autonomously, is what kind of follow-autonomous self independent learning tasks, what kind of learning task is to help classroom teachers.

At the same time, teaching methods should be flexible, depending on the subject matter, adopt different teaching methods. Due to the large class size, teachers in large classes should be divided into different study groups, group learning and to establish operational mechanisms, each group should have one or two team leaders, responsible for the group autonomous self independent learning tasks cases registered. Different groups know ourselves in a competitive atmosphere than the science to catch up, to create a good atmosphere for learning in large classes. Taipan to regular exchanges between the teachers, learn, lessons, improve classroom organization and management capabilities. We believe that through good teaching, flexible teaching methods, innovative teaching content and excellent classroom organization and management capacity, class English teacher will do better. In large classes using communicative teaching, cultivating students' independent self-independent learning ability is somewhat difficult, but as long as the teachers and students shared responsibility, perseverance, a lot of hard work, I believe we will achieve good teaching results.

\section{Conclusion}

Communicative teaching is a new teaching method and it has changed the situation of poor foreign language teaching effect for decades. The teaching method is theoretically scientific, reliable, practical strong social effect is obvious. Ten years of teaching practice has proved that students trained in the method of actual use of language ability, able to adapt to the needs of society, it is a teaching method advocated by the reform of teaching.

\section{References}

[1] Zheng Xinmin, Li Jingyuan. Fujian Foreign Language, Vol. 6 (2014) No 53, p.25-26

[2] Wang Qunyong. Foreign Language Teaching and Research, Vol. 12 (2015) No 27, p.74-76

[3] Qun Yi. Journal of the Shanghai Foreign Language Institute, Vol. 30 (2004) No 19, p.144-145

[4] Wang Kuailiang. Fujian Foreign Language, Vol. 29 (2011) No 27, p.21-23

[5] Sun Jing. Foreign Language Teaching and Research, Vol. 8 (2013) No 27, p.57-60 